NASA/TM-2002-211897/REV1

\title{
DC Bus Regulation With a Flywheel Energy Storage System
}

Barbara H. Kenny

Glenn Research Center, Cleveland, Ohio

Peter E. Kascak

University of Toledo, Toledo, Ohio 
Since its founding, NASA has been dedicated to the advancement of aeronautics and space science. The NASA Scientific and Technical Information (STI) Program Office plays a key part in helping NASA maintain this important role.

The NASA STI Program Office is operated by Langley Research Center, the Lead Center for NASA's scientific and technical information. The NASA STI Program Office provides access to the NASA STI Database, the largest collection of aeronautical and space science STI in the world. The Program Office is also NASA's institutional mechanism for disseminating the results of its research and development activities. These results are published by NASA in the NASA STI Report Series, which includes the following report types:

- $\quad$ TECHNICAL PUBLICATION. Reports of completed research or a major significant phase of research that present the results of NASA programs and include extensive data or theoretical analysis. Includes compilations of significant scientific and technical data and information deemed to be of continuing reference value. NASA's counterpart of peerreviewed formal professional papers but has less stringent limitations on manuscript length and extent of graphic presentations.

- TECHNICAL MEMORANDUM. Scientific and technical findings that are preliminary or of specialized interest, e.g., quick release reports, working papers, and bibliographies that contain minimal annotation. Does not contain extensive analysis.

- CONTRACTOR REPORT. Scientific and technical findings by NASA-sponsored contractors and grantees.
- CONFERENCE PUBLICATION. Collected papers from scientific and technical conferences, symposia, seminars, or other meetings sponsored or cosponsored by NASA.

- SPECIAL PUBLICATION. Scientific, technical, or historical information from NASA programs, projects, and missions, often concerned with subjects having substantial public interest.

- TECHNICAL TRANSLATION. Englishlanguage translations of foreign scientific and technical material pertinent to NASA's mission.

Specialized services that complement the STI Program Office's diverse offerings include creating custom thesauri, building customized databases, organizing and publishing research results ... even providing videos.

For more information about the NASA STI Program Office, see the following:

- Access the NASA STI Program Home Page at http://www.sti.nasa.gov

- E-mail your question via the Internet to help@sti.nasa.gov

- Fax your question to the NASA Access Help Desk at 301-621-0134

- Telephone the NASA Access Help Desk at 301-621-0390

- Write to:

NASA Access Help Desk

NASA Center for AeroSpace Information 7121 Standard Drive

Hanover, MD 21076 
NASA/TM-2002-211897/REV1

\section{Bus Regulation With a Flywheel Energy Storage System}

Barbara H. Kenny

Glenn Research Center, Cleveland, Ohio

Peter E. Kascak

University of Toledo, Toledo, Ohio

Prepared for the

Power Systems Conference

sponsored by the Society of Automotive Engineers

Coral Springs, Florida, October 29-31, 2002

National Aeronautics and

Space Administration

Glenn Research Center 


\section{Document Change History}

This printing, numbered as NASA/TM-2002-211897/REV1, January 2003, replaces the previous version in its entirety, NASA/TM-2002-211897, October 2002.

Page 9: Figures 23, 24, and 25 were modified

Page 10: Motor parameters were changed

Available from

NASA Center for Aerospace Information 7121 Standard Drive

Hanover, MD 21076
National Technical Information Service 5285 Port Royal Road Springfield, VA 22100

Available electronically at http:/ /gltrs.grc.nasa.gov 


\title{
DC Bus Regulation With a Flywheel Energy Storage System
}

\author{
Barbara H. Kenny \\ National Aeronautics and Space Administration \\ Glenn Research Center \\ Cleveland, Ohio 44135 \\ Peter E. Kascak \\ University of Toledo \\ Toledo, Ohio 43606
}

\begin{abstract}
This paper describes the DC bus regulation control algorithm for the NASA flywheel energy storage system during charge, charge reduction and discharge modes of operation. The algorithm was experimentally verified in [1] and this paper presents the necessary models for simulation. Detailed block diagrams of the controller algorithm are given. It is shown that the flywheel system and the controller can be modeled in three levels of detail depending on the type of analysis required. The three models are explained and then compared using simulation results.
\end{abstract}

\section{INTRODUCTION}

The NASA Glenn Research Center is presently developing technologies in several areas to enable the use of flywheels as energy storage devices on future space systems. One of the key elements of a flywheel energy storage system is the electric machine which acts as a motor to store energy and acts as a generator when supplying energy to the loads. The machine must be properly controlled during all operating modes for the flywheel system to function correctly.

A new control algorithm which acts to regulate the operation of the flywheel electric machine in both charge (motoring) and discharge (generating) modes was described in [1]. The new algorithm mimics the operation of a battery system by charging the flywheel with constant current during charge mode and regulating the $\mathrm{DC}$ bus voltage during discharge mode. This paper continues the previous work by focusing on simulation and analysis of the proposed algorithm which was demonstrated experimentally in [1]. Block diagrams are used to describe the algorithm in more detail and to show how the overall system can be modeled. Three levels of detail are modeled and compared ranging from the most simplistic, which assumes an ideal motor controller, to the complex, which includes the inverter switching harmonics.

\section{SYSTEM DESCRIPTION}

Figure 1 shows a high level block diagram of a portion of a spacecraft power management and distribution (PMAD) system. The solar arrays provide power to the load and charging current to the flywheel during insolation. The flywheel provides power to the load during eclipse. The three required modes of control and the corresponding current and voltage relationships are documented in Table 1.

The system is in charge mode as long as the solar array is producing enough current to meet both the charging current command, $I_{\text {charge, and the required }}^{*}$ load current, l load. The system moves into charge reduction mode when the load current demand plus the charging current command exceeds the capability of the solar array. In this mode, the flywheel is still charging ( $\left.\right|_{\text {flywheel }}$ is still positive), but with a current less than the commanded charging current value.

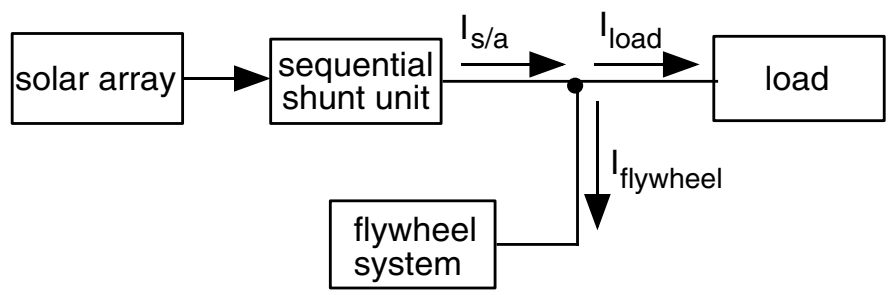

Figure 1: Basic block diagram of spacecraft PMAD.

\begin{tabular}{|c|c|c|}
\hline Mode & Current & DC Bus Voltage \\
\hline $\begin{array}{c}\text { Full Sun } \\
\text { "Charge" }\end{array}$ & $\begin{array}{c}\mathrm{I}_{\mathrm{S} / \mathrm{a}}=\mathrm{I}_{\text {load }}+\mathrm{I}_{\text {charge }}^{*} \\
\mathrm{I}_{\text {flywheel }}=\mathrm{I}_{\text {charge }}^{*}\end{array}$ & $\begin{array}{c}\text { Regulated by } \\
\text { solar array system }\end{array}$ \\
\hline $\begin{array}{c}\text { Partial Sun } \\
\text { "Charge } \\
\text { Reduction" }\end{array}$ & $\begin{array}{c}\mathrm{I}_{\text {load }}+\mathrm{I}_{\text {charge }}^{*}>\mathrm{I}_{\mathrm{S} / \mathrm{a}}> \\
\mathrm{I}_{\text {load }} \\
\mathrm{I}_{\text {charge }}^{*}>\mathrm{I}_{\text {flywheel }}>0\end{array}$ & $\begin{array}{c}\text { Regulated by } \\
\text { flywheel system }\end{array}$ \\
\hline $\begin{array}{c}\text { Eclipse } \\
\text { "Discharge" }\end{array}$ & $\begin{array}{c}\mathrm{I}_{\text {load }}=-\mathrm{I}_{\text {flywheel }} \\
\mathrm{I}_{\text {flywheel }}<0\end{array}$ & $\begin{array}{c}\text { Regulated by } \\
\text { flywheel system }\end{array}$ \\
\hline
\end{tabular}

Table 1: Flywheel system operating mode characteristics. 
Finally, in discharge mode the solar array is providing no current to the load and the flywheel current is negative. Note that these relationships are the same as in a system with battery storage.

\section{SYSTEM (PLANT) MODEL}

A simple model of the electrical system is shown in Figure 2. The capacitor, $\mathrm{C}_{\text {filter, }}$, filters the inverter current and acts to stiffen the DC bus voltage. The flywheel current, I flywheel, will be positive for charging and negative for discharging. The inverter current, $i_{i n v}$, can also be positive or negative. It will consist of a DC component approximately equal to $\mathrm{I}_{\text {flywheel }}$ and an AC ripple component due to the high frequency switching of the inverter that is approximately equal to $\mathrm{i}_{\mathrm{C}}$.

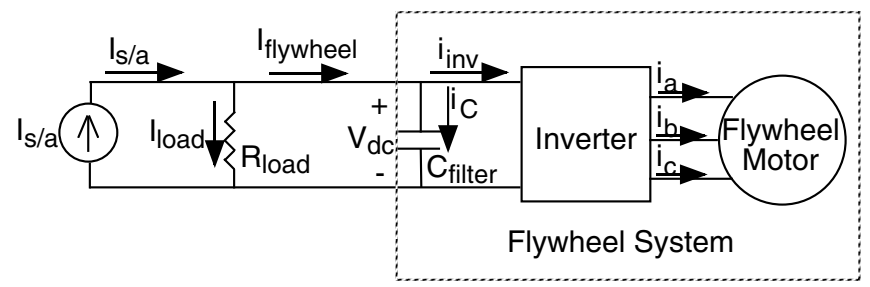

Figure 2: Basic spacecraft electrical model.

The corresponding block diagram model is shown in Figure 3. The solar array current, $\mathrm{I}_{\mathrm{s} / \mathrm{a}}$, is a variable input to the model. It acts as a voltage dependent current source during charge mode, a current source during charge reduction mode and is equal to zero during discharge mode (eclipse operation). The exact characteristics of the $I_{s / a}$ block are determined by the solar array controls of the particular spacecraft.

An additional input to the model that was not shown in Figure 1 is $i_{\text {disturbance. }}$ This is the current that would result if a load is added to or removed from the system. The additional load current, $i_{\text {disturbance, should }}$ have a minimal effect on the DC bus voltage if the voltage regulation is working properly.

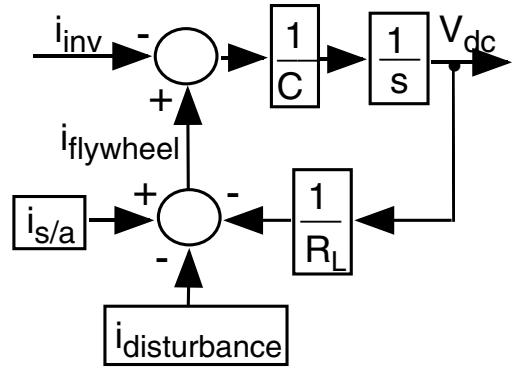

Figure 3: Block diagram of basic spacecraft electrical model.
Finally, the inverter current, $\mathrm{i}_{\mathrm{inv}}$, is the control variable that controls $I_{\text {flywheel }}$ in charge mode and $V_{d c}$ in discharge and charge reduction modes. However, the inverter current is not an independent variable; rather, it is a result of the motor operation. The relationship between the motor and the inverter current will be shown next.

\section{POWER RELATIONSHIPS}

The power into the inverter, $P_{\text {inv }}$, is given by the product of the inverter current, $\mathrm{i}_{\mathrm{inv}}$, and the DC bus voltage as shown in (1). The power out of the inverter is the electrical power to the motor, $P_{\text {elec. If }}$ the inverter losses are neglected, the power into the inverter is equal to the motor power, $\mathrm{P}_{\text {elec }}$.

$$
\mathrm{P}_{\mathrm{inv}}=\mathrm{i}_{\mathrm{inv}} \mathrm{V}_{\mathrm{dc}} \cdot \mathrm{P}_{\text {elec }}
$$

The mechanical shaft power of the motor is equal to the product of the torque and the mechanical speed as shown in (2).

$$
P_{\text {mech }}=\tau_{e} \omega_{\text {rmech }}
$$

The machine electrical power is equal to the mechanical power plus or minus (motoring or generating, respectively) any losses. In the flywheel application, the flywheel shaft is suspended on magnetic bearings and operated in a vacuum. Thus the typical machine losses, friction and windage, are essentially eliminated so the electrical power is approximately equal to the mechanical shaft power as shown in (3). Additionally, eddy current and hysteresis losses are minimal in the permanent magnet machine used in this application.

$$
P_{\text {inv }}=i_{\text {inv }} V_{\text {dc }} \cdot P_{\text {elec }} \cdot P_{\text {mech }}=\tau_{\mathrm{e}} \omega_{\text {rmech }}
$$

The inverter current can then be expressed as a function of the motor torque, the shaft speed and the DC bus voltage as shown in (4).

$$
\mathrm{i}_{\mathrm{inv}}=\frac{\tau_{\mathrm{e}} \omega_{\mathrm{rmech}}}{\mathrm{V}_{\mathrm{dc}}}
$$

Also, the speed of the machine is related to the torque and the inertia, J, as shown in equation (5). In this application, the torque, $\tau_{e}$, is used only to accelerate or decelerate the machine; there is no external load torque.

$$
\tau_{e}=J \frac{d \omega_{r m e c h}}{d t}
$$


These equations are expressed in block diagram format and combined with Figure 3 to form a system model as shown in Figure 4. This block diagram expresses the basic relationship between the motor torque, the inverter current, and the dc bus voltage.

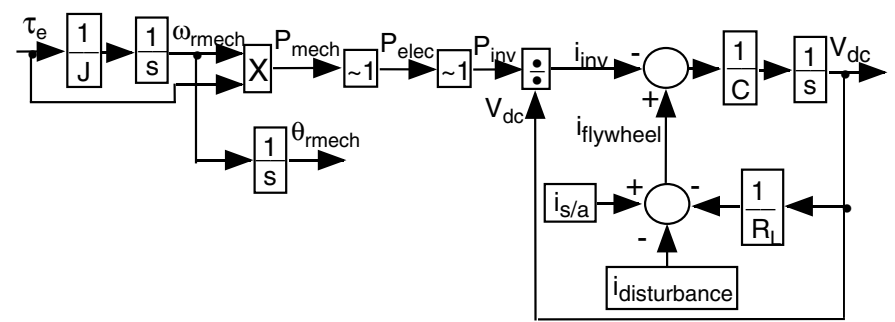

Figure 4: System block diagram from motor torque to DC bus voltage.

\section{MOTOR TORQUE CONTROL}

From the previous discussion it can be seen that the flywheel current (charge mode) or the DC bus voltage (discharge and charge reduction modes) can be controlled if the inverter current is controlled. It can also be seen that the inverter current can be controlled if the motor torque is controlled. There are two basic approaches to achieving accurate, high bandwidth motor torque control described in the literature: field orientation control (vector control) and direct torque control. In the NASA effort we have focused on the more established field orientation approach although direct torque control is a possibility for future research.

In the field orientation technique, the measured currents are transformed to $d-q$ variables in a synchronously rotating rotor reference frame [2]. Torque control is achieved by properly controlling the resulting currents, $\mathrm{i}_{\mathrm{qs}}^{r}$ and $\mathrm{i}_{\mathrm{ds}}^{r}$. The expression for torque is given in (6) [2].

$$
\tau_{e}=\frac{3}{2} \frac{P}{2}\left[\left(L_{d} i_{d s}^{r}+\lambda_{a f}\right) i_{q s}^{r}-\left(L_{q} i_{q s}^{r}\right) i_{d s}^{r}\right]
$$

The d-axis current, $i_{d s}^{r}$, is generally commanded to zero which results in a linear relationship between the machine torque and current as shown in equation (7). This relationship can also be added to the block diagram representation as shown in Figure 5.

$$
\tau_{e}=\frac{3}{2} \frac{P}{2} \lambda_{\text {af }} \mathrm{i}_{\mathrm{q} s}^{r}
$$

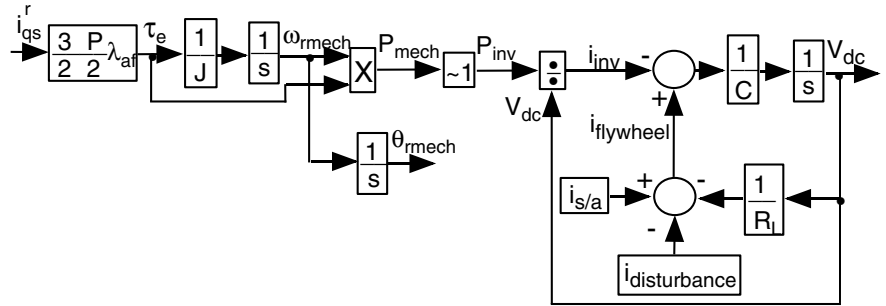

Figure 5: System block diagram (plant model) from motor current to DC bus voltage.

Finally, the relationship between the motor current and the inverter current can be derived by substituting equation (7) into (4) where $\omega_{r}$, the electrical frequency, equals the product of the number of pole pairs, $\mathrm{P} / 2$, and $\omega_{\text {rmech }}$, the mechanical frequency. The result is shown in equation (8).

$$
\mathrm{i}_{\mathrm{qs}}^{\mathrm{r}}=\mathrm{i}_{\mathrm{inv}} \frac{2 \mathrm{~V}_{\mathrm{dc}}}{3 \omega_{\mathrm{r}} \lambda_{\mathrm{af}}}
$$

\section{CONTROLLER}

Given the basic plant model shown in Fig. 5 and the relationship between the inverter current and the motor current shown in (8), the flywheel control algorithms will now be described. The basic procedure is as follows:

1. Calculate the commanded inverter current value, $\mathrm{I}_{\text {inv }}{ }^{*}$, to achieve the desired $\mathrm{I}_{\text {flywheel }}$ in charge mode and the desired $\mathrm{V}_{\mathrm{dc}}$ in discharge and charge reduction modes.

2. Convert the commanded inverter current, $\mathrm{i}_{\text {inv }}{ }^{*}$, to a commanded motor current, $\mathrm{i}_{\mathrm{qs}}^{\mathrm{r}^{*}}$, using equation (8).

3. Regulate the motor current, $\mathrm{i}_{\mathrm{q}}^{r}$, to the commanded value, $\mathrm{i}_{\mathrm{qs}}^{\mathrm{r}}$, through a high bandwidth current regulator and the field orientation motor control algorithm.

The available feedback variables are the dc bus voltage, $V_{d c}$, the flywheel system current, $I_{\text {flywheel }}$, the motor speed, $\omega_{r}$, the motor position, $\theta_{r}$, and the motor currents. Note that in the steady state condition, when the DC bus voltage is constant, $\mathrm{i}_{\mathrm{C}}=0$ and $\mathrm{i}_{\mathrm{inv}}=$ Iflywheel. 


\section{CHARGE CONTROL}

The block diagram representation of the charge control algorithm is shown in Figure 6. There are two components to the controller: the proportional integral (PI) and the feed-forward (FF). The respective outputs are summed together to form the $i$ inv command. The inverter current command is then converted to a motor current command through the relationship given in (8).

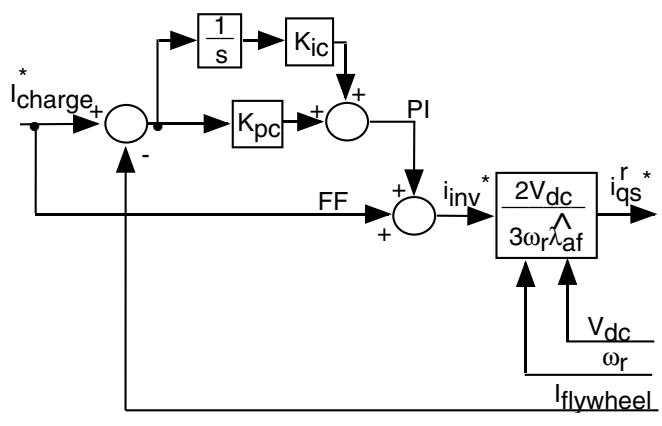

Figure 6: Charge control block diagram.

The PI portion of the controller is a standard technique to implement closed loop control. Proportional and integral gains, $\mathrm{K}_{\mathrm{pc}}$ and $\mathrm{K}_{\mathrm{ic}}$, act on the $\mathrm{DC}$ current error $\left(I_{\text {charge }}^{*}-I_{\text {flywheel }}\right)$ which results in the $\mathrm{i}_{\mathrm{inv}}^{*}$ command. One drawback to PI control acting alone is that the system must wait for an error signal before a control adjustment is made. The larger the gains of the PI, the faster the response to the error becomes. However there is a limit on the gains; too large of gains will either lead to an unwanted system response to noise or an unstable response. One technique that can be used to minimize the dependence on the PI controller is feedforward control. In feedforward control, the necessary input signal, $i_{\text {inv }}^{*}$, is calculated which will produce the desired output signal, Iflywheel. The calculation is based on the value of the commanded

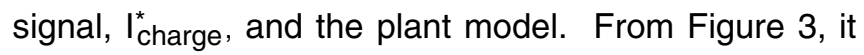
can be seen that in steady state conditions, if the inverter current, $i_{i n v}$, equals the commanded current,

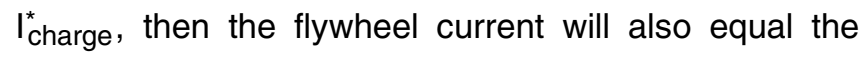
commanded current because the capacitor current, $\mathrm{i}_{\mathrm{C}}$, is zero in steady state. This is the basis of the feedforward control.

Using the PI controller with feedforward as shown in Figure 6 results in an accurate and fast system response. The PI portion ensures the system converges to the set point while the feedforward portion gives a fast response without high PI gains.
The block diagram representation of the discharge and charge reduction control algorithm is shown in Figure 7. There are two components to the controller: the proportional integral (PI) and the disturbance decoupling (DD). In the PI portion, proportional and integral gains, $\mathrm{K}_{\mathrm{pd}}$ and $\mathrm{K}_{\mathrm{id}}$, act on the $\mathrm{DC}$ voltage error $\left(\mathrm{V}_{\text {flywheel }}^{*}-\mathrm{V}_{\mathrm{dc}}\right)$ to create the $\mathrm{i}_{\mathrm{inv}}$ command. The negative gain is required in the $\mathrm{PI}$ control because the inverter current is considered positive when it is entering the inverter (Fig. 2). This means that if the DC bus voltage is to increase, for example if $\left(V_{\text {flywheel }}^{*}\right.$ - $\left.V_{d c}\right)$ is positive, then the inverter current must actually be negative; it must come from the inverter to the load and the capacitor.

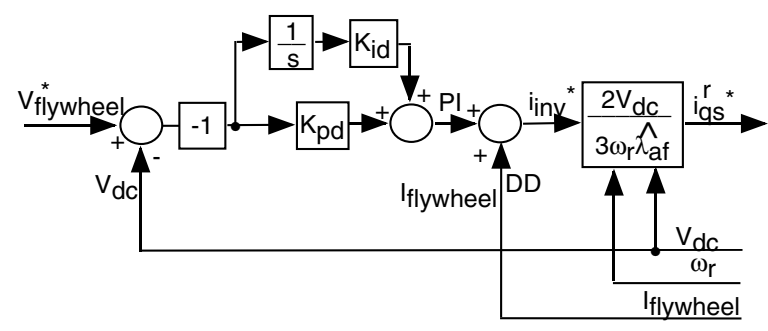

Figure 7: Discharge and charge reduction control block diagram.

When the system is operating in charge mode, the solar array system regulates the DC bus voltage. This means that if there is a change in the load ( $i_{\text {disturbance }}$ ) the solar array current, $I_{s / a}$, will increase or decrease so as to cancel out the disturbance and keep the DC bus voltage at a constant value (see Fig. 3). However, when the system is operating in discharge or charge reduction mode, the solar array current will not be adjusted to maintain the DC bus voltage. Instead, an increase or decrease in load (i $i_{\text {disturbance }}$ ) will cause an increase or decrease in the flywheel current, Iflywheel. The inverter current must compensate for this change if the $\mathrm{DC}$ bus voltage is to be maintained.

The PI controller will eventually respond to an additional load because an increase or decrease in the flywheel current, I Ilywheel, will result in either a decrease or an increase in the DC bus voltage respectively. However, in this system the effect of the disturbance, Iflywheel, is actually measured and fed back to the controller. This means that if a change in Iflywheel $_{\text {occurs, a corresponding command to increase }}$ or decrease the inverter current can easily be given immediately, without waiting for an increase or decrease in the DC bus voltage. This is known as disturbance decoupling control. 
Using the PI controller with disturbance decoupling as shown in Figure 7 results in an accurate and fast system response for the discharge and charge reduction controller. The PI portion ensures the system converges to the set point while the disturbance decoupling portion results in quick changes in commanded current in response to an increase or decrease in load.

\section{COMBINED CHARGE/DISCHARGE CURRENT/ VOLTAGE REGULATOR (CDCVR)}

The two controllers shown in Figs. 6 and 7 are combined to form the overall Charge/Discharge Current/Voltage Regulator (CDCVR) controller shown in Figure 8. The system is in charge mode (current regulation) when the solar array provides enough current to meet both the load demands and the charging current to the flywheel system. Otherwise, the system is in charge reduction or discharge mode which means the flywheel system is regulating the DC voltage bus.

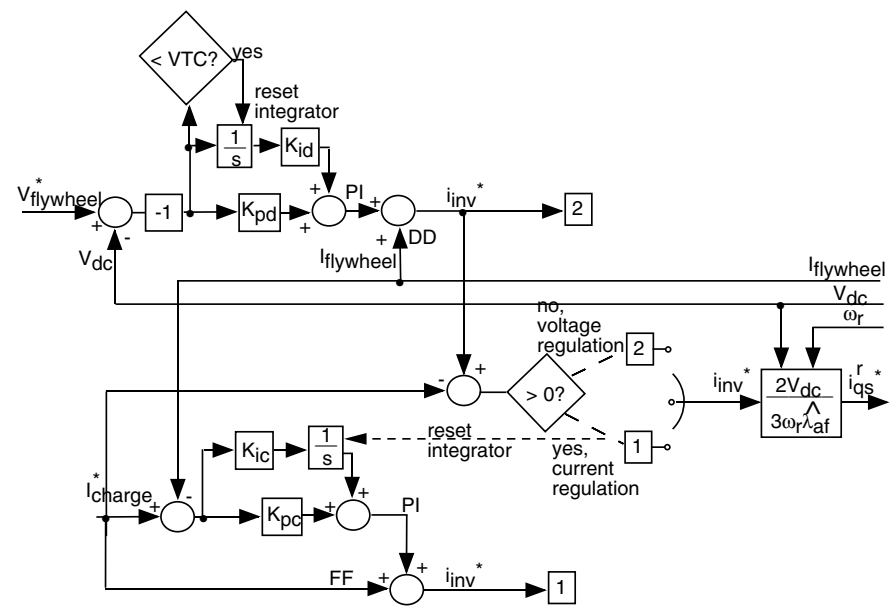

Figure 8: CDCVR control block diagram.

The transition from current regulation (Fig. 6) to voltage regulation (Fig. 7) is accomplished in the following manner. The solar array regulates the bus voltage to a set point value higher than the flywheel regulation set point as long as the solar array current is sufficient to provide both the load and the charging current, $I_{\text {charge. }}^{*}$ Once the solar array current begins to drop off, the DC bus voltage begins to fall and the flywheel current, $1_{\text {flywheel, }}$ also drops. This transition is detected in the controller by comparing the difference between the actual DC bus voltage and the flywheel set point voltage to the "voltage transition constant,"
VTC, as seen in Figure 8. Once this difference is less than the VTC, the integrator in the PI portion of the controller is reset. This reduces the $\mathrm{i}_{\text {inv }}^{*}$ command at point 2 to a value slightly larger than $I_{\text {flywheel }}$. This value is then compared to the charge current set point,

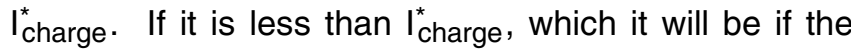
solar array is not producing enough current, then the system transitions into charge reduction mode where the DC bus voltage is regulated by the flywheel system.

Similarly, as the system moves from eclipse into sunlight, the solar array will produce more and more current. When the solar array produces enough current to meet the load demand, the $\mathrm{i}_{\mathrm{inv}}^{*}$ command at point 2 in the controller will become positive. When it exceeds the charge current set point, $\mathrm{I}_{\text {charge, the }}^{*}$ integrator in the current regulator portion of the controller is reset and the system transitions back into charge mode where the flywheel system regulates the current into the flywheel and the solar array system regulates the $\mathrm{DC}$ bus voltage.

It is worth noting that the three modes of operation: charge, charge reduction and discharge, were originally defined based on a battery energy storage system. The flywheel energy storage system is capable of regulating the DC bus voltage at all times, obviating the need for current and voltage regulation modes and the transition between them. This would result in an overall simpler control strategy, even when considering the necessary provisions to prevent overspeed or over-current operation. This type of control will be investigated in future efforts.

\section{OVERALL SYSTEM MODEL}

The simplest end-to-end system model for the current control (charge mode) and voltage control (charge reduction and discharge modes) are shown in Figures 9 and 10 respectively. These models essentially assume a perfect motor controller and current regulator and no losses in the motor or in the inverter. The models can be made progressively more accurate (and more complex) by adding more realistic transfer functions to the blocks that are initially approximated as ideal. The most important of these is the $\frac{i_{q s}^{r}}{i_{q s}^{r^{*}}}$ transfer function which will be discussed next. 


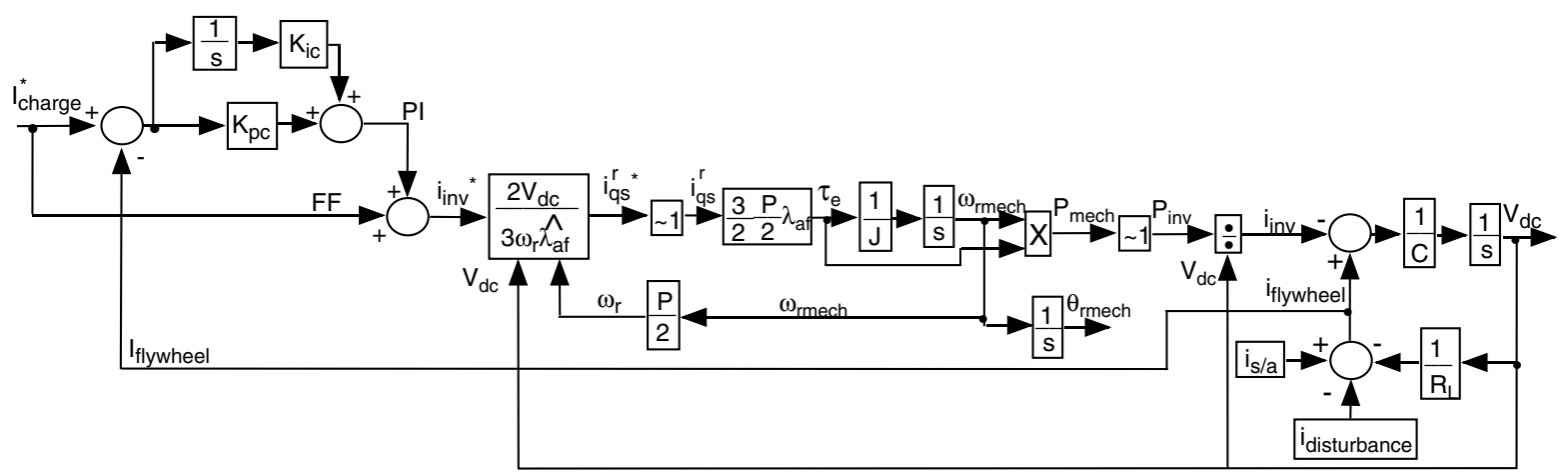

Figure 9: Simplified end-to-end system block diagram for current regulation (charge mode).

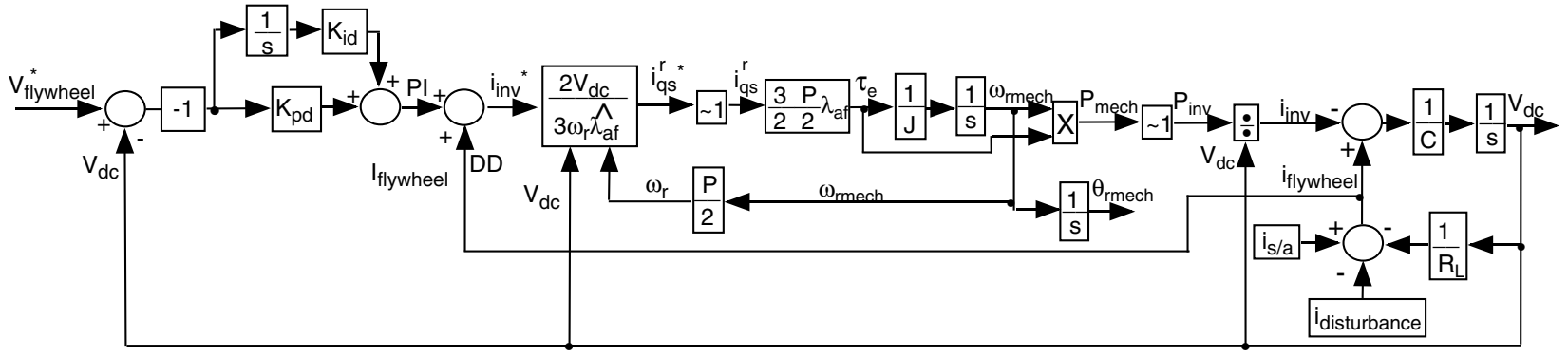

Figure 10: Simplified end-to-end system block diagram for voltage regulation (charge reduction and discharge modes).

\section{MOTOR CURRENT TRANSFER FUNCTION}

A more accurate representation of the transfer function between the commanded current, $\mathrm{i}_{\mathrm{qs}}^{\mathrm{r}^{*}}$, and the actual current, $i_{q s}^{r}$, requires three additional components: the current regulator, the inverter PWM, and the motor model. This section addresses these three pieces.

\section{Current Regulator}

The charge and discharge/charge reduction algorithms result in a motor q-axis current command as can be seen from Figs. 6, 7 and 8 . To achieve this current, a current regulator must be used. A synchronous frame current regulator is a common choice in motor drive application [3]. The basic form is a PI control on each of the two currents, $i_{q s}^{r}$ and $i_{d s}^{r}$, as shown in Figure 11. Each current regulator operates on DC quantities because the control variables are in the rotor reference frame. This means that the PI gains are independent of the fundamental frequency of the actual motor current and can be set for the desired torque response.

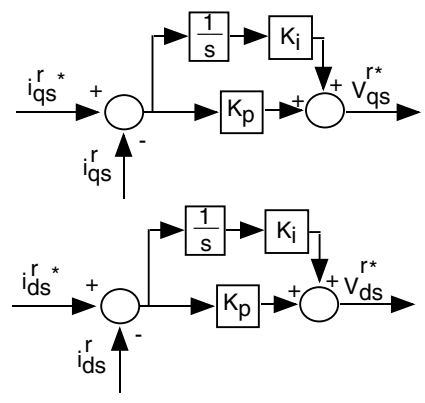

Figure 11: Synchronous frame current regulator for motor currents.

\section{$\underline{\text { Inverter PWM }}$}

The output of the current regulator is rotor reference frame voltage commands, $v_{\mathrm{qs}}^{r^{*}}$ and $v_{\mathrm{ds}}^{r^{*}}$. These are converted to stationary reference frame commands, $v_{\mathrm{qs}}^{\mathrm{s}^{*}}$ and $\mathrm{v}_{\mathrm{ds}}^{\mathrm{s}^{*}}$, through the transformation given in (9) where $\theta_{r}$ is the rotor angle [4]. The stationary reference frame commands are $A C$ voltages that are synthesized from the DC bus voltage through a pulse width modulation (PWM) algorithm known as space 
vector modulation (SVM). The SVM algorithm calculates the necessary duty cycles for each switch to synthesize the required $A C$ voltage from the available DC bus. Equations (10), (11) and (12) give the method used to calculate the duty cycles for the "high" side switches of the inverter [5]. The "low" side switch duty cycles are the inverse of the high side ones.

$$
\begin{gathered}
{\left[\begin{array}{c}
\mathrm{V}_{\mathrm{q}}^{\mathrm{s}^{*}} \\
\mathrm{~V}_{\mathrm{d}}^{\mathrm{s}^{*}}
\end{array}\right]=\left[\begin{array}{cc}
\cos \theta_{\mathrm{r}} & \sin \theta_{\mathrm{r}} \\
-\sin \theta_{\mathrm{r}} & \cos \theta_{\mathrm{r}}
\end{array}\right]\left[\begin{array}{c}
\mathrm{V}_{\mathrm{q}}^{\mathrm{r}^{*}} \\
\mathrm{~V}_{\mathrm{d}}^{\mathrm{r}^{*}}
\end{array}\right]} \\
{\left[\begin{array}{c}
\mathrm{v}_{\mathrm{a}}^{*} \\
\mathrm{v}_{\mathrm{b}}^{*} \\
\mathrm{v}_{\mathrm{c}}^{*}
\end{array}\right]=\left[\begin{array}{cc}
1 & 0 \\
-\frac{1}{2} & \frac{\sqrt{3}}{2} \\
-\frac{1}{2} & \frac{\sqrt{3}}{2}
\end{array}\right]\left[\begin{array}{c}
\mathrm{v}_{\mathrm{qs}}^{\mathrm{s}^{*}} \\
\mathrm{v}_{\mathrm{ds}}^{\mathrm{s}^{*}}
\end{array}\right]} \\
{\left[\begin{array}{c}
\mathrm{d}_{\mathrm{a}}^{*} \\
\mathrm{~d}_{\mathrm{b}}^{*} \\
\mathrm{~d}_{\mathrm{c}}^{*}
\end{array}\right]=\frac{1}{\mathrm{v}_{\mathrm{dc}}}\left[\begin{array}{c}
\mathrm{v}_{\mathrm{a}}^{*}-\mathrm{v}_{\mathrm{o}} \\
\mathrm{v}_{\mathrm{b}}^{*}-\mathrm{v}_{\mathrm{o}} \\
\mathrm{v}_{\mathrm{c}}^{*}-\mathrm{v}_{\mathrm{o}}
\end{array}\right]+\left[\begin{array}{c}
\frac{1}{2} \\
\frac{1}{2} \\
\frac{1}{2}
\end{array}\right]} \\
\mathrm{v}_{\mathrm{o}}=\frac{\max \left(\mathrm{v}_{\mathrm{a}}^{*}, \mathrm{v}_{\mathrm{b}}^{*}, \mathrm{v}_{\mathrm{c}}^{*}\right)+\min \left(\mathrm{v}_{\mathrm{a}}^{*}, \mathrm{v}_{\mathrm{b}}^{*}, \mathrm{v}_{\mathrm{c}}^{*}\right)}{2}
\end{gathered}
$$

For simulation purposes, there are several ways to model this block. The simplest technique is to neglect the PWM harmonics altogether which means that the voltage applied to the machine is exactly equal to the voltage commanded by the current regulator. This is a good model for an initial evaluation of the control methodology because it executes quickly and the results give a good indication of the expected performance.

Another technique is to calculate $v_{q s}^{s^{*}}$ and $v_{d s}^{s^{*}}$ using the duty cycles given in (11), the DC bus voltage and the PWM switching frequency. The resulting voltages are a series of pulses from the DC bus that are applied to the machine. This simulation is quite a bit slower because each PWM pulse is calculated but the effect of the switching harmonics on the system current and voltage can be studied.

Finally, the switches and diodes that form the inverter could be explicitly simulated with their respective characteristics (for example, turn-on time, on-state resistance, reverse recovery, etc.) and characteristics such as switching and conduction losses could be studied. However, this would have the longest execution time of the three types of models. In this paper, only the first two methods to model the inverter are considered.

\section{Motor Model}

The motor model is based on the differential equations governing the performance of the PM machine as given in [2]. A block diagram of the electrical portion of the motor model is shown in Figure 12.

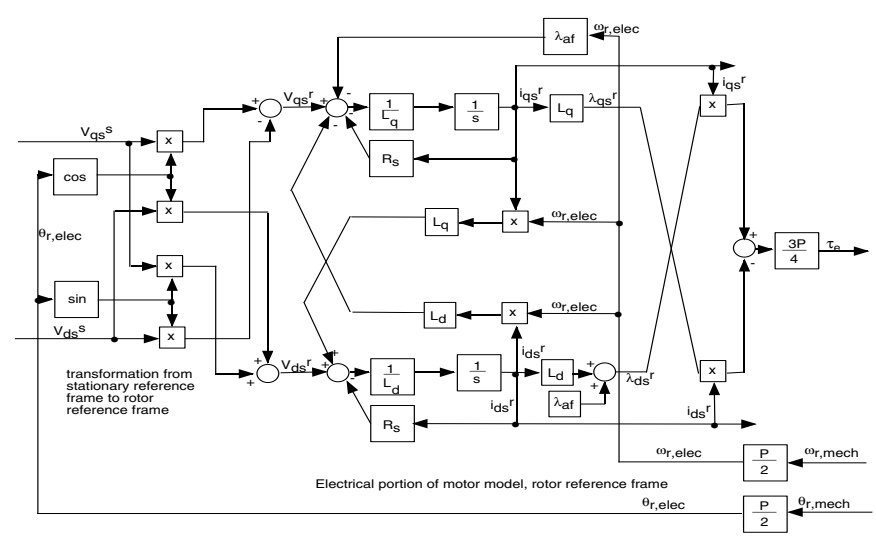

Figure 12: Block diagram of PM motor.

\section{COMPLETE SYSTEM MODEL}

The entire system model, with the current regulator, inverter and motor, is shown in Figure 13. Three models can be derived from Figure 13 depending on which blocks are used. The simplest version, referred to in the simulation results section as the "simple model", does not include the middle three blocks and was given in Figure 9 for charge and Fig. 10 for discharge. This model

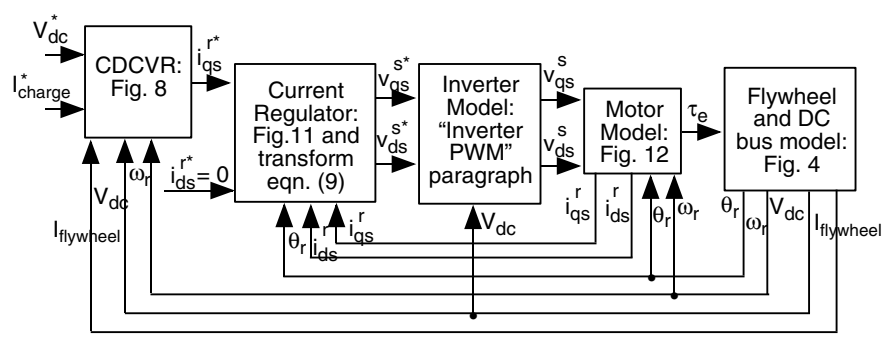

Figure 13: Overall system model.

neglects the electrical dynamics of the motor control and assumes perfect current regulation. The "simple model" is suitable for initial large system simulations of the flywheel with the rest of the spacecraft PMAD.

The next level of fidelity includes all of the blocks of Figure 13 except for the center inverter one. This model neglects the inverter losses and PWM switching harmonics. This is suitable to study the overall 
effectiveness of the PM motor control and different current regulators on the system performance. This model is referred to as the "motor model" in the simulation section.

Finally, all five blocks can be included in the simulation so the effects of the switching harmonics can be seen. This simulation takes four to five times longer to execute than the previous ones so is best used when issues specifically related to switching harmonics are studied. It is referred to as the "PWM model" in the simulation section.

\section{SIMULATION RESULTS}

There are three groups of gain parameters to set in the controller algorithm: the charge mode $\mathrm{PI}$, the discharge mode PI (voltage regulation) and the motor current regulator $\mathrm{PI}$. In addition, one estimated motor parameter, $\lambda_{\text {af }}^{\wedge}$, is necessary. In the following simulations, the PI gains were initially determined and then not varied from simulation to simulation. Simulation results are shown from the three models with three motor parameter estimates: $\lambda_{\text {af }}^{\wedge}=\lambda_{\text {af }}$, and $\lambda_{\text {af }}^{\wedge}=.8 \lambda_{\text {af }}$ and $\lambda_{\text {af }}^{\wedge}=1.2 \lambda_{\text {af }}$. In addition, the poor performance of the controller without feedforward or disturbance decoupling is also shown.

The PI gains for the current regulator were set at $\mathrm{K}_{\mathrm{p}}=1.2$ and $\mathrm{K}_{\mathrm{i}}=3000$. These gains give a torque response bandwidth of about $1 \mathrm{kHz}$ for this machine.

The $\mathrm{PI}$ gains for both the discharge and charge controllers were set at $\mathrm{K}_{\mathrm{p}}=1.2$ and $\mathrm{K}_{\mathrm{i}}=12$. Although the tuning is essentially an heuristic process, an initial determination of appropriate gains for the discharge controller can be made in the following manner. If the disturbance decoupling is neglected, $\lambda_{\text {af }}^{\wedge}=\lambda_{\text {af }}$, and the simple model of figure 10 is used, all that remains is a PI controller and a parallel resistor-capacitor (RC) circuit. Essentially, the $\mathrm{PI}$ controller is producing a current command which will force the voltage on the capacitor to the desired value. The "first guess" gains on the PI controller can be set by using pole-zero cancellation where $\frac{K_{p}}{K_{i}}=\frac{1}{R_{L} C}$ and $K_{p}=2 \pi R_{L} C f_{b w}$. A high bandwidth, $f_{b w}$, is not necessary because of the disturbance decoupling in the total controller. The motor parameters, PWM frequency and DC bus voltage are given in the appendix.
Figures 14 through 25 show the simulation results of the three models with three different values of the estimated motor parameter $\lambda_{\text {af }}^{\wedge}$. In each simulation the same charging and discharging profile is used: the system starts off in charge mode with a flywheel speed of $60,000 \mathrm{rpm}$, then the solar array current ramps down to zero, then there is a step change increase in the load at 5 seconds, then the solar array current ramps back up again. The results show the transitions between modes and the accurate DC bus regulation during the discharge and charge reduction modes.

Electrically, it can be seen that the three models give essentially the same results (Figures 14 to 22). The "PWM model" has more ripple on the DC bus voltage due to the switching action as would be expected. There is no fluctuation in the DC bus voltage in response to the additional load at $t=5$ seconds when $\lambda_{\text {af }}^{\wedge}$ is perfectly estimated. Even with a $20 \%$ error in the estimate, the regulation is still excellent.

The motor speeds are shown in Figures 23 to 25 . It can be seen that the simple model motor speed estimate is not as accurate as the other two models. This is due to the fact that any losses in the motor (for example, stator resistance) are not modeled. The PWM model and the motor model results are virtually identical.

Figures 26 and 27 compare the motor voltage for the PWM model and the motor model. Figures 28 and 29 compare the motor current for the PWM model and the motor model. The motor current is seen to be larger in the PWM model than the motor model. This is due to the low inductance of the machine which causes a large switching current ripple on top of the fundamental. In the actual experimental set up, there is a filter between the inverter and the motor which is not yet included in the simulation models. The filter reduces this current ripple.

Finally, Figure 30 shows the response with PI only in the controller: no feedforward and no decoupling inputs, and with the back emf constant estimated improperly where $\lambda_{\text {af }}^{\wedge}=1.2 \lambda_{\text {aff }}$. It can be seen that the transitions between modes are much worse and there is a greater response to the load disturbance. 


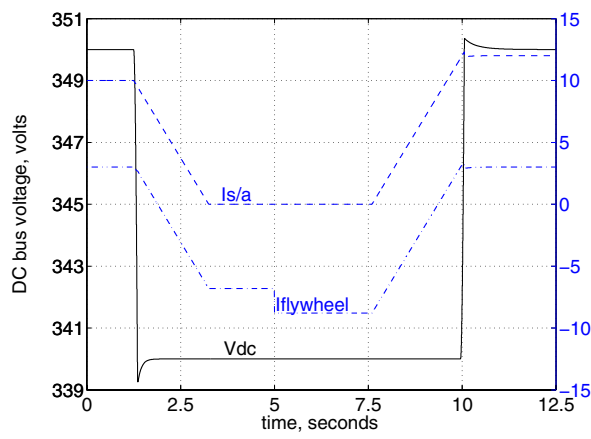

Figure 14: $\lambda_{\text {af }}^{\wedge}=\lambda_{\text {af }}$, simple model.

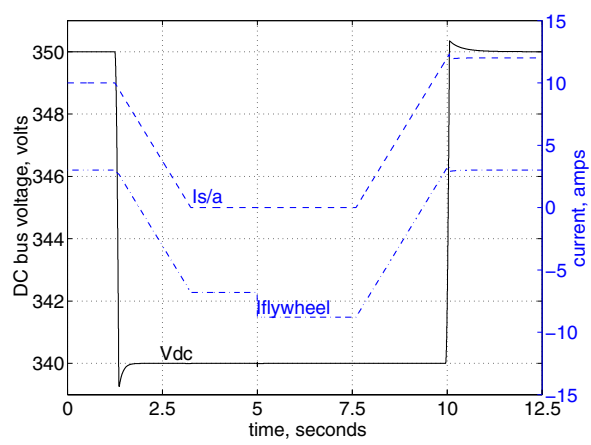

Figure 17: $\lambda_{\text {af }}=\lambda_{\text {af }}$, motor model.

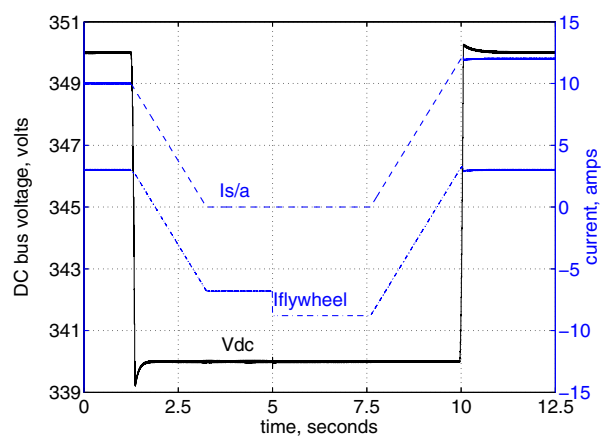

Figure 20: $\lambda_{\text {af }}=\lambda_{\text {af }}$, PWM model.

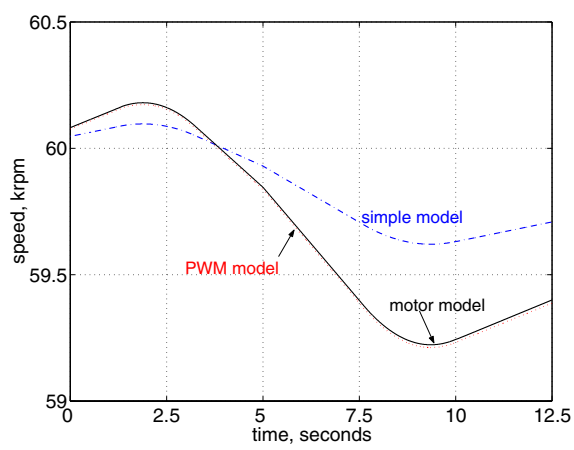

Figure 23: $\lambda_{\text {af }}=\lambda_{\text {af }}$, motor speed.

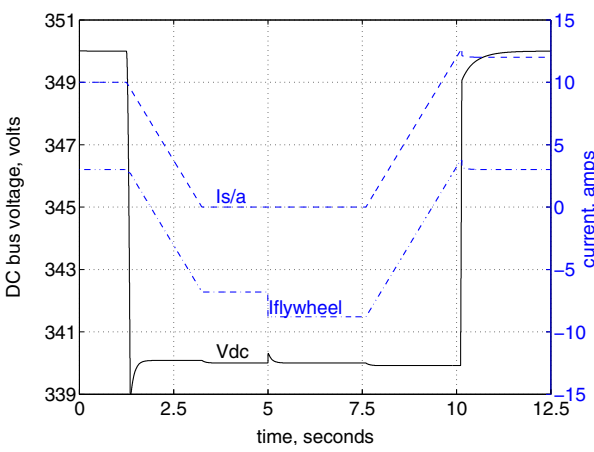

Figure 15: $\lambda_{\text {af }}^{\wedge}=.8 \lambda_{\text {af }}$, simple model.

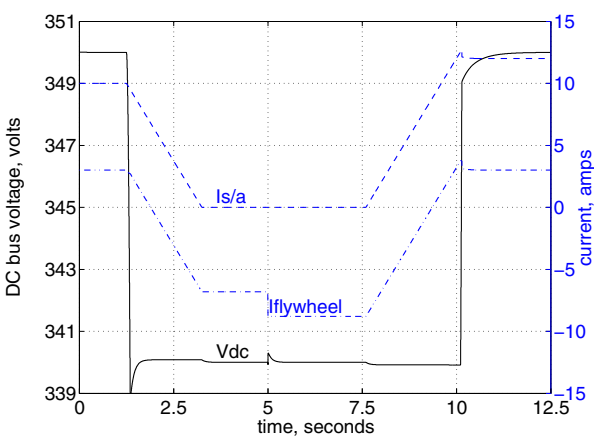

Figure 18: $\lambda_{\text {af }}^{\wedge}=.8 \lambda_{\text {af }}$, motor model.

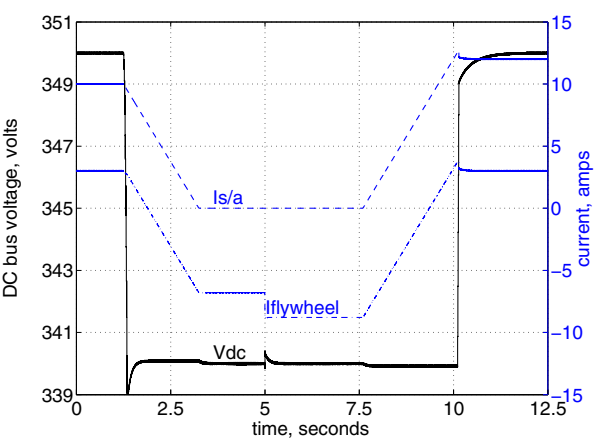

Figure 21: $\lambda_{\text {af }}^{\wedge}=.8 \lambda_{\text {af }}$, PWM model.

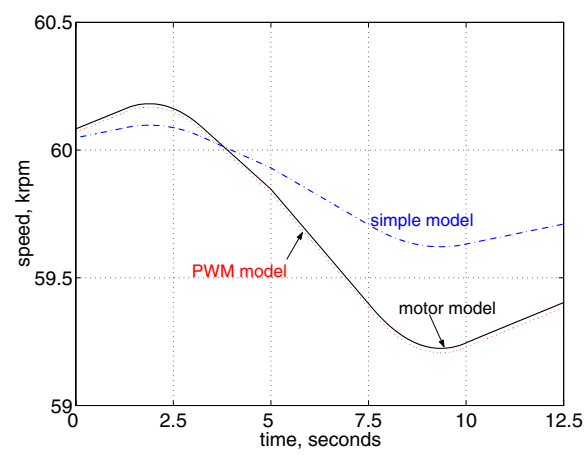

Figure 24: $\lambda_{\text {af }}=.8 \lambda_{\text {af }}$, motor speed.

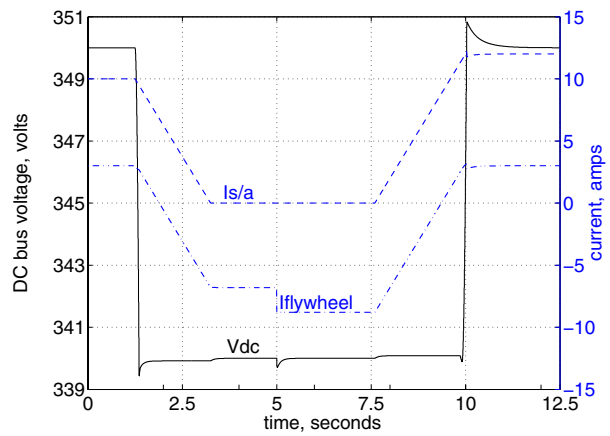

Figure 16: $\lambda_{\text {af }}=1.2 \lambda_{\text {af }}$, simple model.

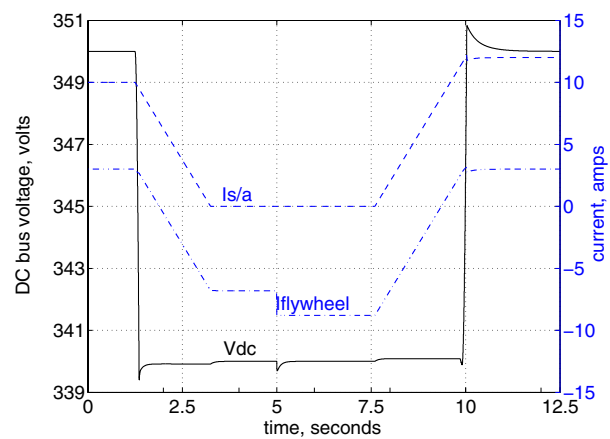

Figure 19: $\lambda_{\text {af }}=1.2 \lambda_{\text {af }}$, motor model.

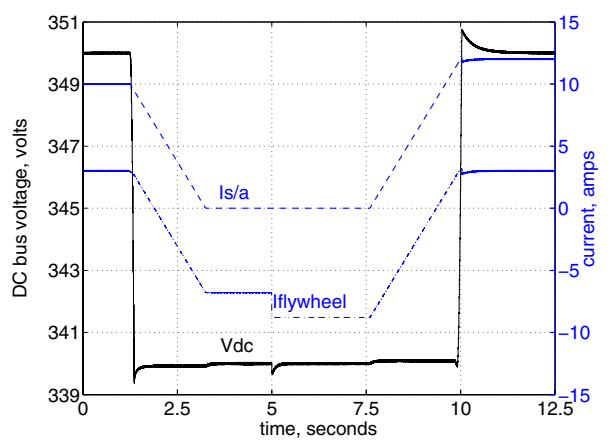

Figure 22: $\lambda_{\text {af }}^{\wedge}=1.2 \lambda_{\text {af }}$, PWM model.

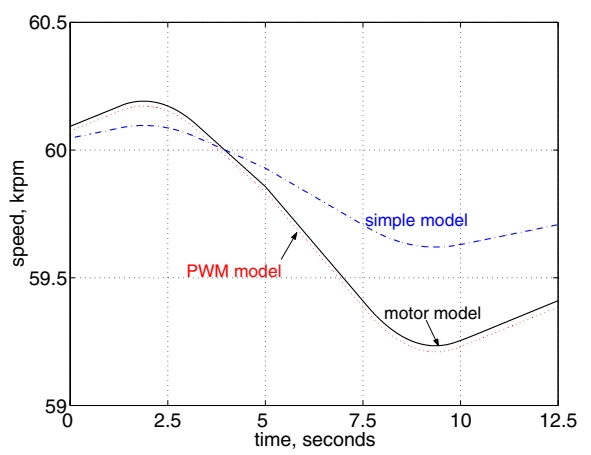

Figure 25: $\lambda_{\text {af }}=1.2 \lambda_{\text {af }}$, motor speed. 


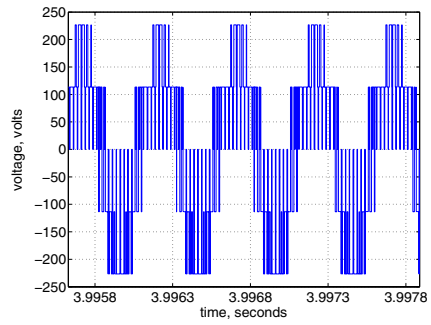

Figure 26: $\lambda_{\text {af }}^{\wedge}=\lambda_{\text {af }}$, motor voltage, PWM model.

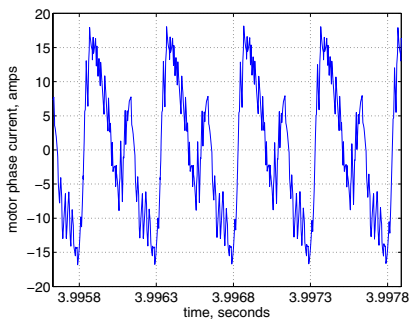

Figure 28: $\lambda_{\text {af }}^{\wedge}=\lambda_{\text {af }}$, motor current, PWM model.

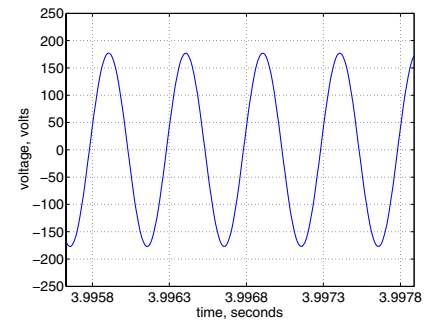

Figure 27: $\lambda_{\text {af }}=\lambda_{\text {af }}$, motor voltage, motor model.

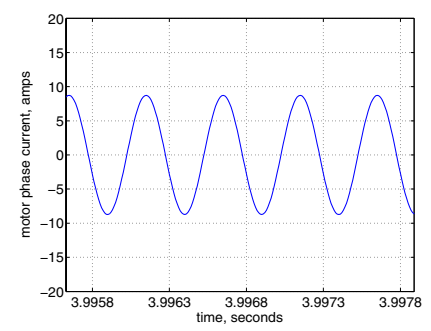

Figure 29: $\lambda_{\text {af }}=\lambda_{\text {af }}$, motor current, motor model.

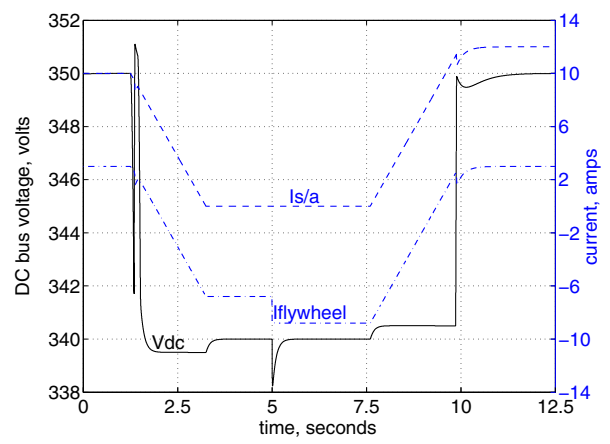

Figure 30: $\lambda_{\text {af }}^{\wedge}=1.2 \lambda_{\text {af }}$, system response without feedforward and disturbance decoupling in the controller.

\section{CONCLUSIONS}

This paper has presented detailed block diagrams of the DC bus regulation control algorithm for the NASA flywheel energy storage system which was previously experimentally verified [1]. The block diagrams are necessary for system simulations to predict performance. It was shown that the flywheel system and the controller can be modeled in three levels of detail depending on the type of analysis required. The three models give similar electrical results however for the most accurate representation of the motor speed the simple model is not appropriate.
The simulation results showed the control algorithm to be effective even in the presence of parameter errors. The controller successfully transitions between current regulation in charge mode and DC bus voltage regulation in discharge mode.

Future work will include evaluating a modified flywheel control such that the flywheel system maintains the DC bus regulation continuously, during both charge and discharge operation.

\section{REFERENCES}

1. Kascak, P, B. Kenny, T. Dever, W. Santiago, R. Jansen, "International Space Station Bus Regulation with NASA Glenn Research Center Flywheel Energy Storage System Development Unit”, July 2001 IECEC Conference Proceedings, Savannah, Georgia, 2001.

2. Krishnan, Ramu, Permanent Magnet Synchronous and Brushless DC Motor Drives: Theory, Operation, Performance, Modeling, Simulation, Analysis and Design, Virginia Tech., Blacksburg, Virginia, 1999.

3. Rowan, T. and R. Kerkman, "A New Synchronous Current Regulator and an Analysis of CurrentRegulated PWM Inverters", IEEE Transactions on Industry Applications, Vol IA-22, No. 4, July/August 1986, pp. 678-690.

4. Kenny, B.H., P. Kascak, et. al, "Advanced Motor Control Test Facility for NASA GRC Flywheel Energy Storage System Technology Development Unit", July 2001 IECEC Conference Proceedings, Savannah, Georgia, 2001.

5. Mohan, Ned, Workshop Proceedings, NSF-Faculty Workshop on Teaching of Courses in Power Electronics and Electric Drives, Tempe, Arizona, January 3-5, 2002.

\section{DEFINITIONS, ACRONYMS, ABBREVIATIONS}

I,V Current, voltage where capital letters denote a DC quantity.

i,v Current, voltage where small letters denote an AC quantity.

$\mathrm{I}^{*}, \mathrm{~V}^{*} \quad$ Commanded current, commanded voltage; the asterisk denotes a commanded value.

$\omega_{r} \quad$ Electrical rotor speed, radians per second

$\omega_{\text {rmech }}$ Mechanical rotor speed, radians per second

$P \quad$ Number of poles in motor

$\lambda_{\text {af }}^{\wedge} \quad$ Back EMF constant, volt-seconds; the carrot denotes an estimated quantity. 


\section{APPENDIX}

Motor parameters: $R_{S}=.06 \Omega, L_{q}=139 \mu \mathrm{H}, L_{d}=116 \mu \mathrm{H}$, $\lambda_{\text {af }}=.0141$ volt-sec., $\mathrm{J}=.0153 \mathrm{~kg}-\mathrm{m}^{2}, 4$ pole

DC bus voltage set points: charge mode: 350 volts, discharge mode: 340 volts.

PWM frequency: $40 \mathrm{kHz}$. 


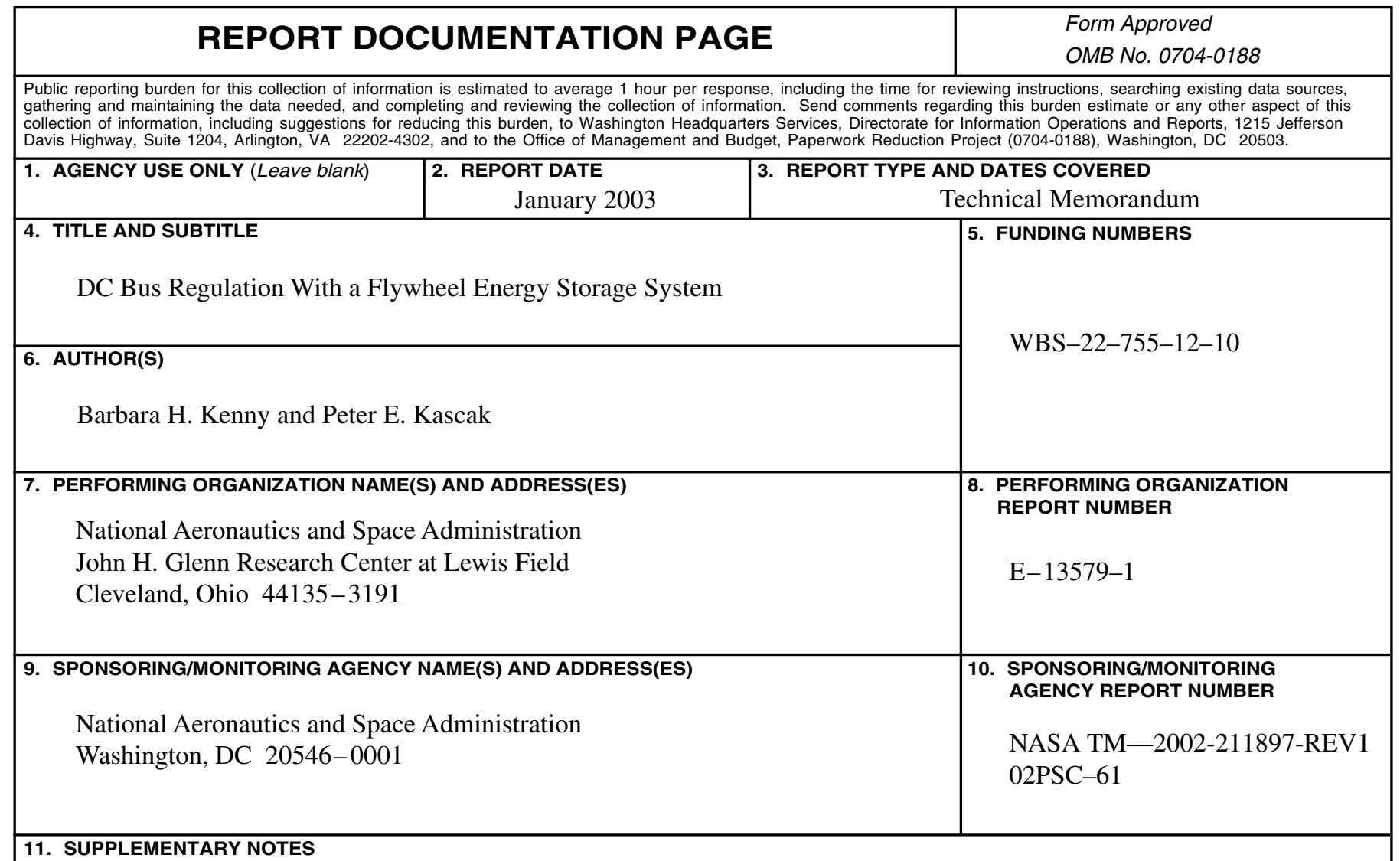

Prepared for the Power Systems Conference sponsored by the Society of Automotive Engineers, Coral Springs, Florida, October 29-31, 2002. Barbara H. Kenny, NASA Glenn Research Center, and Peter E. Kascak, University of Toledo, Toledo, Ohio 43606. Responsible person, Barbara H. Kenny, organization code 5450, 216-433-6289.

12a. DISTRIBUTION/AVAILABILITY STATEMENT

12b. DISTRIBUTION CODE

Unclassified - Unlimited

Subject Categories: 20 and 44

Distribution: Nonstandard

Available electronically at http://gltrs.grc.nasa.gov

This publication is available from the NASA Center for AeroSpace Information, 301-621-0390.

\section{ABSTRACT (Maximum 200 words)}

This paper describes the DC bus regulation control algorithm for the NASA flywheel energy storage system during charge, charge reduction and discharge modes of operation. The algorithm was experimentally verified with results given in a pervious paper. This paper presents the necessary models for simulation with detailed block diagrams of the controller algorithm. It is shown that the flywheel system and the controller can be modeled in three levels of detail depending on the type of analysis required. The three models are explained and then compared using simulation results.

\begin{tabular}{|c|c|c|}
\hline \multicolumn{3}{|l|}{$\begin{array}{l}\text { 14. SUBJECT TERMS } \\
\text { Flywheel energy storage; } \mathrm{S} \\
\text { motor control }\end{array}$} \\
\hline $\begin{array}{l}\text { 17. SECURITY CLASSIFICATION } \\
\text { OF REPORT }\end{array}$ & $\begin{array}{l}\text { 18. SECURITY CLASSIFICATION } \\
\text { OF THIS PAGE }\end{array}$ & $\begin{array}{l}\text { 19. SECURITY CLASSIFICATION } \\
\text { OF ABSTRACT }\end{array}$ \\
\hline Unclassified & Unclassified & Unclassified \\
\hline
\end{tabular}

NSN 7540-01-280-5500 15. NUMBER OF PAGES 16. PRICE CODE 20. LIMITATION OF ABSTRACT 